New Mode of Using the Concave Diffraction Grating.

I GREATLY regret that in a note of mine on a " new mode of using the concave diffraction grating," in the "Astronomical Column " of March 22 (p. 50I), I wronsly interpreted a sentence of Prof Rizzo's article, which led me to think it was inconvenient for him to use the instrument in the usual way. The words "Dr Rizzo investigated this disposition on account of being unable to use the instrument as usually set up," should therefore not have been included THE WRITER OF THE NOTE

\section{Internal Stresses in Iron and Steel.}

CAN you kindly inform me where I may obtain a copy of the researches of General Kalakoutsky on the "Internal Stresses in Cast Iron and Steel," translated by the late Sir William Anderson, F.R.S., Director-General, Royal Ordnance Factories.

Sheffield, March 27. Thos. ANDREws.

THE work in question- "Investigations into the Internal Stresses in Cast Iron and Steel," by General Nicholas Kalakoutsky--was published by George Reveirs, 4 and 5 Graystoke Place, Fetter Lane, E.C., in 1888.

Second-hand copies can occasionally be procured from dealers in technical books. B. H. B.

\section{ELECTRICITY IN WAR.}

TNDER the Presidency of the late Dr. Hopkinson, the Institution of Electrical Engineers established an Electrical Engineer Volunteer Corps affiliated to the Royal Engineers. Lord Kelvin is now its Honorary in warfare, and in consequence of their unfamiliarity with existing apparatus are very likely to quickly notice methods of improving it.

Hitherto many of these men have had a yearly drill in the management of the electrical apparatus in use for submarine mining and home defence.

I would point out that the ordinary volunteer drill of these men is only a part of their preparation for the nervous tension of an enemy's presence. There is no more trying experience than that of a young engineer in a central electric light station when the "peak" of the evening load is coming on, and every appliance is worked to its highest capacity; when the stoker cannot get enough draught for his boilers, and a short-circuit suddenly takes place. It is interesting to note how the man who was nervously afraid of himself beforehand, braces himself up to meet the emergency, and to his own wonder afterwards, manages to do exactly the right thing at the critical moment. A man who has proved his coolness in this sort of way is not likely to be flurried in the field, even when a rain of those most dangerous of all missiles, the $37 \mathrm{~mm}$. Vickers-Maxim shells, are exploding about his search-light.

A few years ago, when Major Crompton vainly urged the necessity for the provision of new apparatus, practice in the use of existing field search-lights, \&c., such as might lead to better designs, and money to enable such better apparatus to be constructed and tested, some of us felt very strongly that the War Office was wasting an invaluable opportunity.

A committee of the Institution of Electrical Engineers was able to assure Major Crompton of considerable

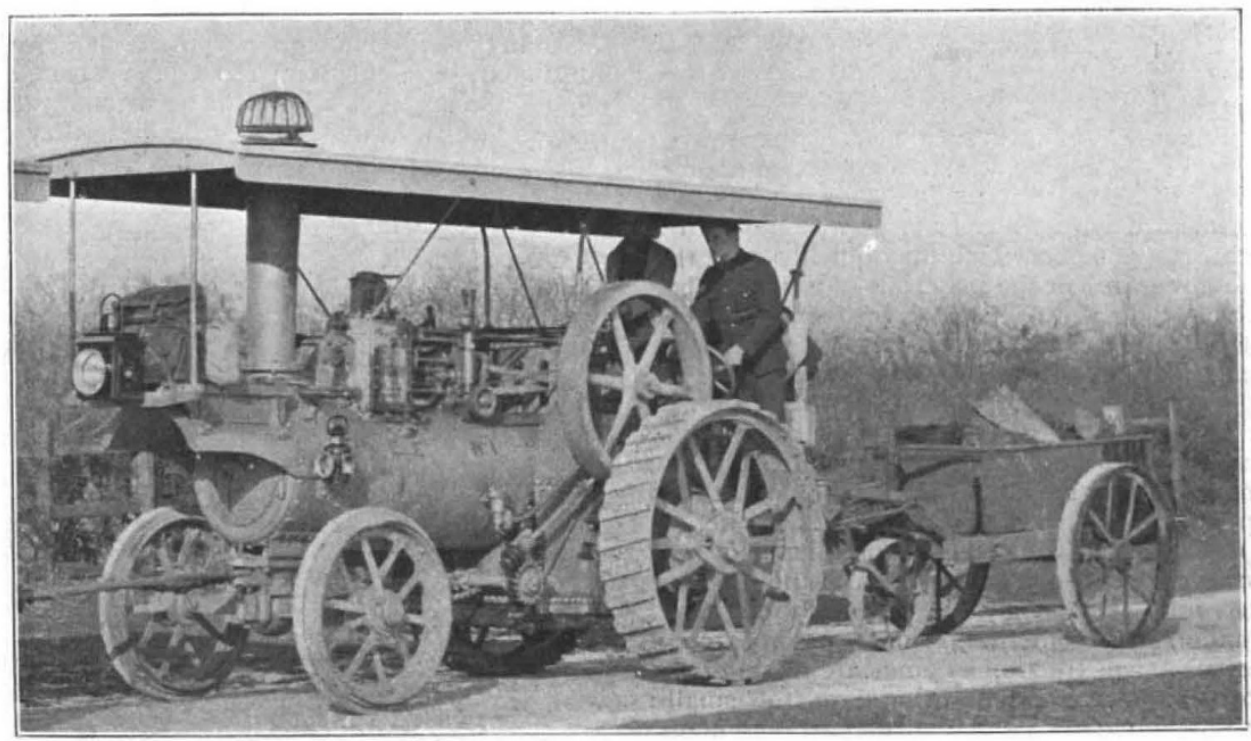

FIG. 1,-Traction engine.

Colonel; the well-known electrical and mechanical engineer, Mr. R. E. Crompton (formerly Captain in the Rifle Brigade) is its Major. It is a corps consisting of 350 young men, most of whom have had a scientific education; they are all engaged every day in practical electrical engineering work; many of them are constantly engaged in inventing new apparatus and improving old apparatus; all of them are athletic, and enjoy such exercise as the volunteer drill affords; many of them are experienced bicyclists; all of them are curious as to the existing applications of electricity NO. I 588 , vOL. 6 I ] pecuniary help in case the War Office gave facilities, and it was proposed that the corps should take up some one problem at a time, and work it out to a thoroughly good practical result. For example, the production of a really good field search-light was proposed. To work awhile with the existing things, which were like ship searchlights carried upon ordinary waggons, and to expend all the ingenuity of the corps upon the creation of a piece of apparatus perfect for military purposes. This involves also the best design of mobile steam engine and dynamo plant ; the best kind of cable, and the best ways of paying 
it out and reeling it in. It also involves the design of the best arrangement of telephonic communication between the generating plant, the lights, and the officers in command and the general officer, possibly miles apart.

Again, is there anything of greater practical importance

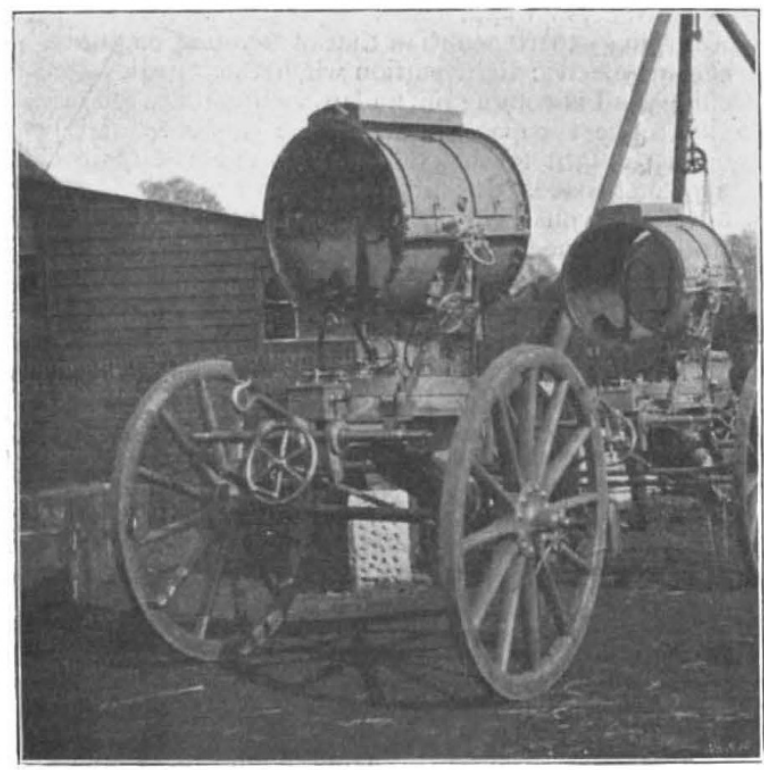

FIG. 2.-Mounted projector

than this? Suppose we have such electric generating plant in the field; the engine, which is a traction engine, may be utilised in actual traction. Or a spare dynamo may be sent forward across a river or up a kopje with a simple winch arrangement, which may quickly be set in position, so that waggons or the materials of a bridge may be hauled across the river, or the heaviest guns may be hauled up the hills, or ammunition hoists or pumps may be set in motion. Electricity gives us the means of transmitting power in great or small quantities to any distance for all sorts of purposes; and Major Crompton imagined the gradual working out of all such problems, one at a time, by this corps of men, whose qualifications were just perfect for such purposes "It is to be remembered that in such work the requirements of war service introduce special conditions such as never have to be taken into account by the ordinary engineer. Everybody understands something about traction engines. Now the best English traction engines are made to run on good roads; their wheels are, therefore, too small ; their tires are too narrow ; their spring arrangements, and therefore their gearing, are quite unsuited for motion on a South African veldt. Not only so, but they are designed for places where the supply of water is plentiful everywhere. A traction engine, using up at least a ton of water every five hours, is not quite what is wanted in a dry country.

I wonder if the War Office officials dream of the number of ways in which the scientific engineer might be made useful. A few really experienced practica! electrical engineers will sometimes get together and unbend and talk of the things that might so easily be done, if instead of appointing third class men to important posts, the Government would really try to utilise the services of good engineers.

I shall not here refer to the fact that temptations are

$$
\text { NO. I } 588 \text {. VOL. } 61\rceil
$$

dangled before the eyes of third class men by unscrupulous contractors; about this side of the subject I do not care to speak. I think merely of the importance of the services of clever experienced men.

Even a good man would perhaps have but little chance of doing much service under existing arrangements. A Government prefers to spend ten millions of pounds in building ships that are something like existing ships, slight improvements on existing models, than to waste, as they would call it, a hundredth part of the sum in making experiments which would teach how ships may really be improved. And so it is in all branches of applied science. Bring forward a cut and dried scheme, perfect ; be prepared to spend your own money in show ing that it is good; if you have sufficient influence your scheme will be tried and may be adopted. But even a powerful clever head of a Government department must show a finished working thing to represent expended money. As this is so generally the case in all Government departments, it is probably not very fair to blame the War Department for not utilising the inventive and experimental talent of the Corps of Electrical Engineer Volunteers. Even if it could justly be blamed, there is now no desire to criticise the past inartion of the War Office. There is no inaction now; Major Crompton has been given a free hand in the equipment of active service contingents. He has worked night and day for two months, and his success has been marvellous. One of these contingents, consisting of fifty-eight men and six officers, started for South Africa a few days ago. Under Captain Lloyd, R.E., it took with it a complete equipment of two search-lights, including four waggons, each carrying 4 tons, and two traction engines, each with its dynamo as well as one spare dynamo, and I am greatly mistaken if this spare dynamo be not before long used as a motor for many useful haulage purposes. The dynamos are multipolar, semi-enclosed, I IO volts; 750 revolutions per minute ; 80 amperes all day, or occasionally 100 amperes. Instead of working the projectors they may work

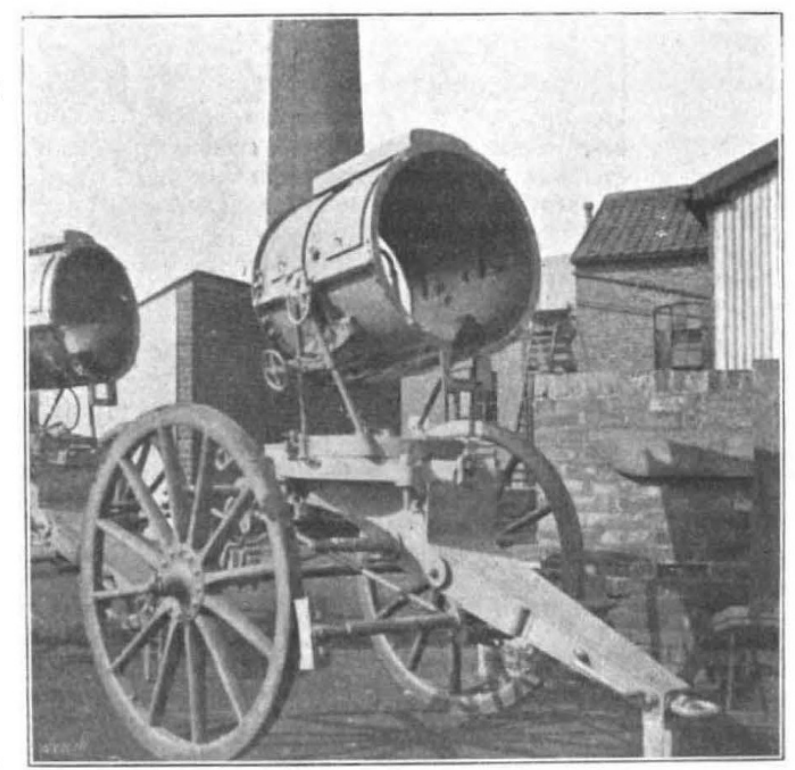

FiG. 3.-Mounted projector.

ordinary arc and incandescent lights for use with night working parties $(24$ arc lights with portable lanterns, as well as 200 incandescent lamps have been sent out). Future dynamos will have spare armatures wound for 
much higher voltagres; also they will be driven from smallei fly wheels by chains instead of belts. The detachment takes with it twenty-five khaki-coloured, long-crank, specially strong bicycles. Fig. I shows the engine, but I am sorry to say that its dynamo has been removed fron its front end and replaced by lugeage. Special spring arrangements at the front end of the engine prevent hurt to the dynamo from jolts. I know of no other compound traction engine whose weight is only 8 tons. I am told that in practice it consumes about 32 pounds of water per hour per electrical horse-power developed a wonderfully good result for so small an eng. ne (maximum electrical power, probably 13). With a little experience this expenditure may be rut down to 28 pounds. It will be part of the regular drill of the men to run a searchlight for a specified time, there being competition as to the expenditure of coal and water. When we consider that these very economical en ines need about 400 pounds of water (they need also about 45 or 50 pounds of coal) per hour, we see the defect of the ordinary traction engine for army transport purposes. A third engine which is groing out with Major Crompton and a second contingent this week will have partial condensation of its steam, so that the watcr will not all be wasted. It is to be hoped that so easily designed a thing as a traction engine with light surface condensing plant condensing all its steam will be in use before long. Major Crompton has had a considerable experience of engines in general, and of traction engines in particular, having carried out experiments on traction for the Indian Government long before he became identified with electrical encineering. I understand that the War Office is now concidering his scheme for working the transport service of an entire division of the army, independently of all railway's.

This is the first time that projectors have been fitted to special trails like gun-carriages. The carriages of riveted best cast steel are strong and light, as may be seen in Figs. 2, 3 and 4 . The wheels are from the Royal Arsenal, and may be replaced if hurt in the field. "The limbers are shown in lig. 5. I'oles and harness equip-

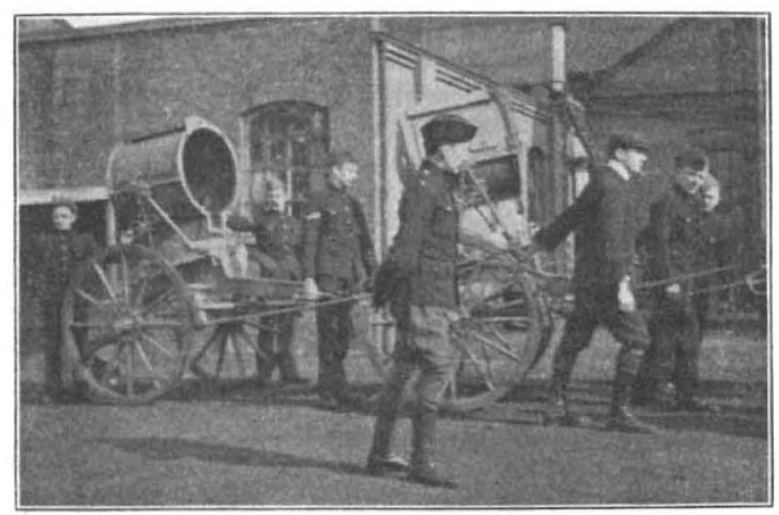

Fic: 4.-Projectors hatuled by men.

ments for ten span of mules have been provided. The projectors may be hauled either by the engines, or by the mules, or by the men. The projectors are novel in design; almost the only feature of existing projectors embodied in them is the barrel. Their mirrors, glasses and divergers are mounted in aluminium. They have gunmetal bases moving in ball run turntables. They may be detached from their carriages and stand on the ground on their four feet. The Coles reflectors are of deposited copper faced with silver, and a thin coat of palladium to prevent tarnishing. The lamp mechanism is new, the pattern service lamp being far ton heavy and clumsy ; moreover, the usual arc-strikıng arrangement would be hammered to pieces by the vibration of the moving carbon when the lamp is travelling about. The new lamp locks the moveable carbon holder in position after the arc is struck, and

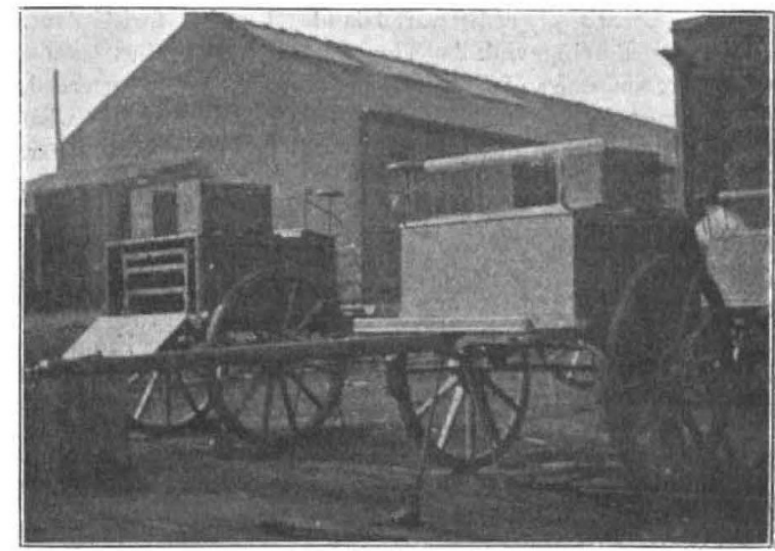

Fic. 5.- Limbers.

the feeding movement is carried out by the shunt coil acting on the other carbon. These search-lights may be stationed a milc or more away from each traction engine, as there may be a fall of 52 volts between dynamo and arc. The main cables are of quite a novel kind. They are concentric cables with an insulated core, one-tenth of a square inch in cross section; they are armoured on the outside hy a copper braiding, which forms the return conductor, but there are other forms of cable and uninsulated copper ropes for returns. The telephone arrangements are novel. Najor Crompton has adopted the Swedish cavalry pattern of instrument, which can be used as a telephone, or the signals may consist of the "buzz" through a high resistance or through a very leaky circuit. On trial, he finds that there is very good speech through the telephones and two miles of bare wire on the wet grass. Of course there will be audible speech for, possibly, six miles, on dry grass. This fine (No. 22) copper wire may be laid from reels fixed on bicycles when the bicycles are going at ten miles an hour; and it may be picked up at a speed of four miles an hour. There is also a supply of the more usual concentric: telephone cable, and twelve sets of combined telephones and bu:\% telegraph instruments have been sent out.

I am not at liberty to publish an account of the novel ideas as to the best use of search-lights which Major Crompton hopes to illustrate when in front of the enemy's position. I think that the whole experiment is a hopeful one. Everybody knows the sort of athletic, energetic young men who are chosen for mountain battery work; they are as resourceful and cat-like as sailor men. Imagine such young men, with, in addition, the qualifications which I have enumerated, and you have some idea of these young electrical engineer volunteers. With Captain Lloyd and Major Crompton in command, it is to be expected that there will be a good return for the expense incurred. The money paid for equipment is only a very small part of the total expense of this experiment. JOHN PFRRY.

NO. I 588, YOL. 61] 